\title{
Regulation of Glycolytic Metabolism in Fresh-cut Carrots under Low Oxygen Atmosphere
}

\author{
Hisashi Kato-Noguchi ${ }^{1}$ and Alley E. Watada ${ }^{2}$ \\ Horticultural Crops Quality Laboratory, Building 002, Beltsville Agricultural Research Center, Agricultural \\ Research Service, U.S. Department of Agriculture, 10300 Baltimore Avenue, Beltsville, MD 20705
}

Additional index words. Daucus carota, ATP : phosphofructokinase, fructose 1,6-bisphosphate, PPi : phosphofructokinase, respiration

\begin{abstract}
Carrot (Daucus carota L.) shreds were stored under a continuous flow of air or $0.5 \%$ and $2 \% \mathbf{O}_{2}($ balance $\mathbf{N}$,) for 9 days at 5 and 15C. The resulting changes in respiration, levels of glycolytic intermediates, and activities of ATP : phosphofructo kinase (ATP-PFK), and PPi : phosphofructokinase (PPi-PFK) were monitored. Carrots under low $\mathrm{O}_{2}$ atmosphere exhibited an increase in $\mathrm{RQ}$ due to a greater reduction in $\mathrm{0}_{2}$ consumption than in $\mathrm{CO}_{2}$ production, and the increase in $\mathrm{RQ}$ was greater at $0.5 \%$ than at $2 \% \mathrm{O}_{2}$ at both temperatures. Fructose 1,6-bisphosphate (F1,6P) accumulated with decreased $\mathrm{O}_{2}$ atmosphere and was 2 -fold greater at $0.5 \%$ than at $2 \% \mathrm{O}_{2}$ atmosphere at both temperatures. The levels of other glycolytic intermediates were not significantly influenced by low $O_{2}$. The increase in PPi-PFK activity occurred at the same time as F1,6P accumulation. A similar relationship was not found with ATP-PFK. These results suggest that PPi-PFK may be involved in regulation of glycolysis under low $\mathrm{O}_{2}$ atmosphere.
\end{abstract}

Much research has been conducted to evaluate the effects of controlled and modified atmosphere on fruits and vegetables (Hardenburg et al., 1990; Isenberg, 1979; Smock, 1979). However, the mode of action of $\mathrm{O}_{2}$ and $\mathrm{CO}_{2}$ on fresh produce is not fully understood (Kader, 1986; Wang, 1990; Weichmann, 1986).

Since very low $\mathrm{O}_{2}$ and very high $\mathrm{CO}_{2}$ atmospheres caused accumulation of acetaldehyde and ethanol in tissues of harvested plants (Kennedy et al., 1992; Thomas, 1929), studies have been undertaken to understand the mechanism for regulation of fermentation in harvested plant parts in response to low $\mathrm{O}_{2}$ and high $\mathrm{CO}_{2}$ (Kanellis et al., 1991; Ke et al., 1994; Leshuk and Saltveit, 1991; Nichols and Patterson, 1987; Smilanick and Fouse, 1989).

Kerbel et al. (1988) studied the effect of high $\mathrm{CO}_{2}$ on glycolysis and reported a significant reduction in the activities of ATP : phosphofructokinase (ATP-PFK) and PPi : phosphofructokinase (PPi-PFK) and in the content of fructose 1,6-bisphosphate (F1,6P) in pear fruit stored under high $\mathrm{CO}_{2}$ atmosphere; a discernible increase in the content of fructose 6-phosphate (F6P) was also observed. To our knowledge, no information is available on the effects of low $\mathrm{O}_{2}$ concentration on glycolytic intermediates and related enzymes in harvested plant tissues.

The objective of this research was to determine the effects of low $\mathrm{O}_{2}$ on glycolysis. Thus, respiration rate, levels of glycolytic intermediates, and certain glycolytic enzymes were determined in carrot root shreds stored under low $\mathrm{O}_{2}$ atmosphere.

\section{Materials and Methods}

Plant materials and treatments. Carrot roots (Daucus carota) were purchased from a local wholesale distributor in Jessup, Md. Uniform roots were washed, peeled, trimmed of their root tips and stem plates, and shredded with a food processor (DLC-10;

Received for publication on 7 Apr. 1995. Accepted for publication 17 July 1995. Use of a company or product name by U.S. Dept. Agriculture does not imply approval or recommendation of the product to the exclusion of others which also may be suitable. We gratefully acknowledge Willard Douglas for excellent technical assistance. The cost of publishing this paper was defrayed in part by the payment of page charges. Under postal regulations, this paper therefore must be hereby marked advertisement solely to indicate this fact.

'Permanent address: Dept. of Bioresource Science, Faculty of Agriculture, Kagawa Univ., Miki-cho, Kagawa 761-07, Japan.

${ }^{2}$ To whom reprint requests should be addressed.
Cuisinunart, East Windsor, N.J.). Shreds (about $50 \mathrm{~mm}$ in length, $5 \mathrm{~mm}$ in width, and $4 \mathrm{~mm}$ thick) were placed in plastic trays (100 $\mathrm{g}$ fresh weight per container), and each tray was stored in a 3.8liter glass jar at 5 and $15 \mathrm{C}$. A stream of air, or $0.5 \%$ or $2 \% \mathrm{O}_{2}$ (balance $\mathrm{N}$,) was metered through the jar at a rate of $10 \mathrm{ml} \cdot \mathrm{min}^{-1}$ at $5 \mathrm{C}$ and $15 \mathrm{ml} \cdot \mathrm{min}^{-1}$ at $15 \mathrm{C}$, which was sufficient to keep $\mathrm{CO}_{2}$ accumulation below $0.3 \%$. Distilled water $(100 \mathrm{ml})$ was placed at the bottom of the jar to maintain a high relative humidity, and the tray was elevated above the water. Oxygen consumption and $\mathrm{CO}$ production of the shreds were measured four times every day with a computer controlled electrochemical $\mathrm{O}_{2}$ analyzer (S-3A/I; Ametec, Pittsburgh, Pa.) and $\mathrm{CO}_{2}$ analyzer (CD-3A; Ametec).

For quantification of glycolytlc intermediates and determination of enzyme activities, one jar for each treatment was removed from storage at various intervals. Then, the carrot shreds were immediate] y frozen in liquid $\mathrm{N}_{2}$ and stored at $-80 \mathrm{C}$ until extraction.

Quantification of glycolytic intermediates. All intermediates were analyzed by standard enzymatic methods adapted from Bergmeyer (1983). Frozen carrot shreds (about $5 \mathrm{~g}$ fresh weight equivalent) were transferred to liquid $\mathrm{N}_{2}$ in a mortar and ground to a fine powder using a pestle. The powder was mixed with $10 \mathrm{ml}$ of $10 \%(\mathrm{w} / \mathrm{v})$ trichloroacetic acid solution for $1 \mathrm{~h}$ at $0 \mathrm{C}$ with occasional shaking. The mixture was then centrifuged at $30,000 \times \mathrm{g}$ for $30 \mathrm{~min}$ at $0 \mathrm{C}$. The supernatant was partitioned 4 times against an equal volume of ether; the lower layer was used for quantification of intermediates.

Quantification was carried out spectrophotometrically by monitoring the oxidation/reduction of NADH/NADP at $340 \mathrm{~nm}$ for 10 to $15 \mathrm{~min}$ at $30 \mathrm{C}$ in $1 \mathrm{ml}$ of triethanolamine buffer (TEA, $\mathrm{pH}$ 7.6) containing the following reagents: $0.5 \mathrm{ml}$ sample, $200 \mathrm{~mm}$ TEA, $0.2 \mathrm{~mm}$ NADP, $5 \mathrm{~mm} \mathrm{MgCl}$ and 0.2 units of glucose 6-phosphate dehydrogenase for glucose 6-phosphate (G6P); the above mixture plus 0.8 units of phosphoglucose isomerase for F6P; $0.5 \mathrm{ml}$ sample, $200 \mathrm{~mm}$ TEA, $20 \mathrm{~mm}$ EDTA, $0.1 \mathrm{~mm} \mathrm{NADH}$, and 0.2 units of glycerol-3-phosphate dehydrogenase (GDH) for glyceraldehyde 3-phosphate (GAP); the above mixture for GAP plus 0.9 units of triosephosphate isomerase (TIM) for dihydroxyacetone phosphate (DHAP); the above mixture for DHAP plus 0.5 units of aldolase for F1,6P; $0.5 \mathrm{ml}$ sample, $100 \mathrm{~nm}$ TEA, $1 \mathrm{~mm}$ EDTA, 0.2 mM NADH and 8 units of glyceraldehyde- 3-phosphate dehydrogenase (GAPDH) for glycerate 1,3-bisphosphate (1,3PGA); $0.5 \mathrm{ml}$ sample, 100 mm TEA, 1 mm EDTA, $0.1 \mathrm{~mm} \mathrm{NADH,} 8 \mathrm{~nm} \mathrm{NaSO}$, 


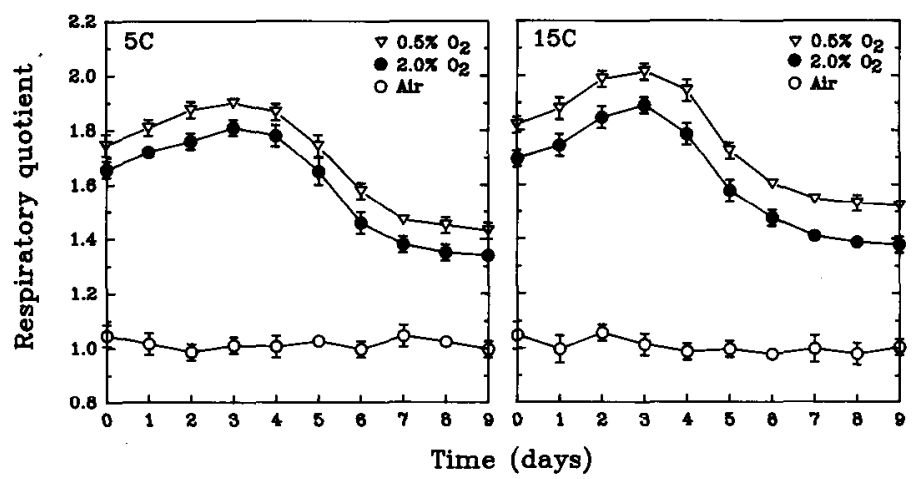

Fig. 1. Effect of $0.5 \%$ and $2 \% \mathrm{O}_{2}$ atmospheres on the RQ of carrot shreds at $5 \mathrm{C}$ and $15 \mathrm{C}$. Means \pm SE from four measurements per day with four jars are shown, The experiment was repeated three times with similar results.

7 mM ATP, 3.6 units of GAPDH, 0.8 units of GDH, 24 units of TIM and 16 units of phosphoglycerate kinase for glycerate 3-phosphate (3 PGA); $0.5 \mathrm{ml}$ sample, $150 \mathrm{~mm}$ TEA, $1.5 \mathrm{~mm}$ EDTA, $0.2 \mathrm{~mm}$ $\mathrm{NADH}, 12 \mathrm{~mm} \mathrm{MgSO}_{4}, 44 \mathrm{~mm} \mathrm{KC1,} 1.7 \mathrm{~mm}$ ADP and 6 units of lactate dehydrogenase for pyruvate (PYR); the above mixture for PYR plus 4 units of pyruvate kinase for phosphoenolpyruvate (PEP); and the above mixture for PEP plus 2 units of enolase for glycerate 2-phosphate (2PGA).

The recovery of glycolytic intermediates through the quantification process was $91 \% \pm 2 \%, 89 \% \pm 3 \%, 88 \$ \pm 2 \%, 89 \% \pm 3 \%$, $91 \% \pm 3 \%, 87 \% \pm 4 \%, 90 \% \pm 2 \%, 90 \% \pm 2 \%, 88 \% \pm 3 \%$, and $89 \%$ $\pm 1 \%$ for G6P, F6P, F1, 6P, GAP, DHAP, 1,3PGA, 3PGA, 2PGA, $\mathrm{PEP}$, and PYR, respectively, as calculated from 5 dedications of the test run with pure glycolytic intermediates in the extracts.

Determination of enzyme activities. Tissue powder $(5 \mathrm{~g}$ fresh weight equivalents) was prepared as described above and mixed with $10 \mathrm{ml}$ solution containing $100 \mathrm{~mm}$ Tris- $\mathrm{HCl}(\mathrm{pH} 7.8), 2 \mathrm{~mm}$ EDTA, $1 \mathrm{mM} \mathrm{MgCl}_{2}, 5 \mathrm{~mm}$ DTT and $2.5 \mathrm{~g}$ insoluble PVP at $0 \mathrm{C}$ for $1 \mathrm{~h}$ with occasional shaking. The mixture was centrifuged at $30,000 \times \mathrm{g}$ for $25 \mathrm{~min}$ and the supernatant used immediately for measurement of enzyme activities.

PPi:phosphofructokinase (PPi-PFK) was assayed spectroophotometrically by monitoring the oxidation of NADH $(0.16 \mathrm{~mm})$ in the following: 1-ml reaction mixture according to Smyth et al. (1984a); $100 \mathrm{~mm}$ HEPES-NaOH ( $\mathrm{pH} 7.8$ ), $4 \mathrm{~mm}$ magnesium acetate, $2 \mathrm{~mm}$ F6P, 1.2 units of aldolase, 14 units of TIM, 1.8 units of GDH, $0.05 \mathrm{ml}$ of extract, and $1 \mathrm{~mm}$ PPi to initiate the reaction. Twenty $\mu \mathrm{l}$ of $100 \mu \mathrm{M}$ fructose 2,6-phosphate $(\mathrm{F} 2,6 \mathrm{P})$ was added after a linear rate of production was obtained. The same mixture was used for determination of ATP: phosphofructokinase (ATP-PFK), except that PPi was replaced by $1 \mathrm{~mm}$ ATP, and F2,6P was omitted.

One unit is the amount of enzyme that catalyzed the conversion of $1 \mu \mathrm{mol}$ of substrate per min under our conditions. The recovery of enzyme activity through the quantification process was $95 \% \pm$ $3 \%$ and $97 \% \pm 5 \%$ for PPi-PFK, and ATP-PFK, respectively, according to 5 repeated assays with pure enzymes in the extracts. Protein was determined according to Bradford ( 1976) with bovine gamma globin as a standard.

Three entirely separate experiments were conducted, and determinations and assays were replicated at least twice in each experiment.

\section{Results and Discussion}

Oxygen uptake and $\mathrm{CO}_{2}$ production of carrot shreds were less under low $\mathrm{O}_{2}$ than in air atmosphere, and the reduction of $\mathrm{O}_{2}$ uptake

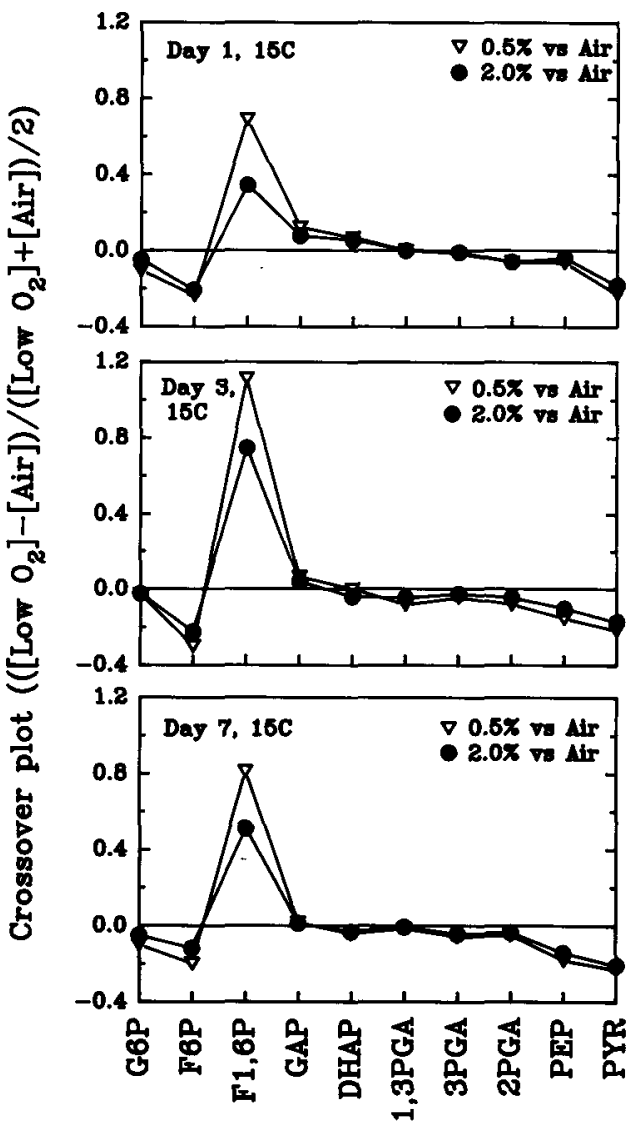

Fig. 2. Crossover plot of glycolytic intermediates in carrot shreds held in $0.5 \% \mathrm{O}_{2}, 2 \%$ $\mathrm{O}_{2}$, or air atmospheres at 1,3 , and 5 days at $15 \mathrm{C}$. The content of the intermediate of samples in low $\mathrm{O}_{2}$ and air for the specific day were used to calculate the crossover plot, The zero line represents no change between low $\mathrm{O}_{2}$ and air atmospheres. Each point represents the mean of two to three determinations with the same extract. The experiment was repeated three times with similar results.

was greater than the reduction in $\mathrm{CO}_{2}$ production (data not shown). This resulted in a larger RQ for samples in low $\mathrm{O}_{2}$ than in air. The $\mathrm{RQ}$ was also greater at the lower $\mathrm{O}_{2}$ atmosphere (Fig. 1), which has been noted with other fruits and vegetables (Leshuk and Saltveit, 1991; Solomos, 1983; Weichmann, 1987). During storage, the RQ of samples in air remained unchanged, whereas those in low $\mathrm{O}_{2}$ increased until day 4 , followed by a decrease until day 7 at both 5 and 15C. Glycolysis operates under both aerobic and anaerobic conditions, but when $\mathrm{O}_{2}$ is deprived even for short periods of time, many plants accelerate glycolysis and the glycolytic pathway replaces the Krebs cycle as the main source of energy (Kennedy et al., 1992; Mocquot et al., 1981).

The amount of each glycolytic intermediate in low $\mathrm{O}_{2}$ was compared with that in air using a crossover plot of the data for days 1,3, and 7 at 5 and $15 \mathrm{C}$ (Figs. 2 and 3). Data on the $\mathrm{X}$-axis indicate there were no differences between samples in low $\mathrm{O}_{2}$ and air atmospheres. The most significant change was the accumulation of F1 ,6P, with the accumulation being greater at 15C. F6P, PEP, and PYR contents of samples in low $\mathrm{O}_{2}$ were lower than those in air, and the contents of the other intermediates tested remained unchanged.

The amount of F1 ,6P in samples in air did not change during storage, but increased in samples under low $\mathrm{O}_{2}$. The pattern of increase differed with storage temperature (Fig. 4). The F1 ,6P content of samples in $2 \% \mathrm{O}_{2}$ at $5 \mathrm{C}$ increased slightly and remained at a plateau, whereas those in $0.5 \% \mathrm{O}_{2}$ increased up to day 3 and then decreased slightly. At $15 \mathrm{C}, \mathrm{F} 1,6 \mathrm{P}$ increased at both $0.5 \%$ and $2 \% \mathrm{O}_{2}$ and decreased after day 3 , with the changes being greater at $0.5 \% \mathrm{O}_{2}$ 


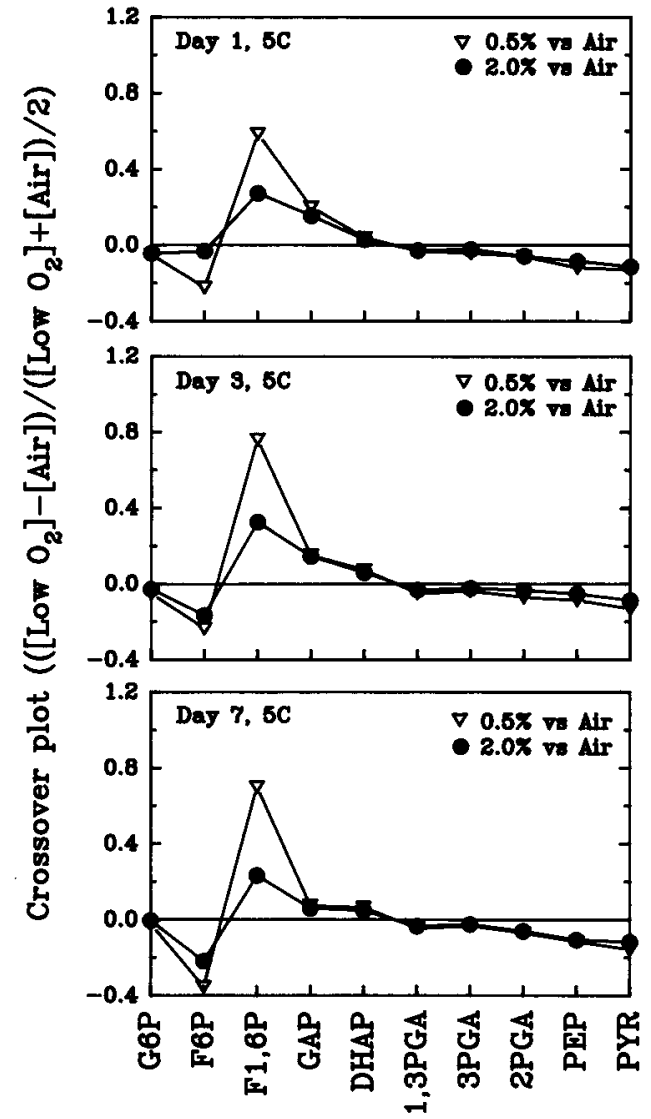

Fig. 3. Crossover plot of glycolytic intermediates in carrot shreds held in $0.5 \%$, $2 \%$ $\mathrm{O}_{2}$, and air atmospheres at 1,3 , and 5 days at $5 \mathrm{C}$. Other conditions are the same as described in Fig. 2.

than at $2 \% \mathrm{O}_{2}$. The greater accumulation of $\mathrm{F} 1,6 \mathrm{P}$ at $15 \mathrm{C}$ was probably due to the higher rate of metabolism at $15 \mathrm{C}$ than at $5 \mathrm{C}$.

The activities of PPi-PFK and ATP-PFK in carrots under low $\mathrm{O}_{2}$ and air atmospheres are shown in Figs. 5 and 6. Activity of PPiPFK increased sharply until day 3 and then decreased in samples under low $0_{2}$, whereas it remained unchanged in samples stored under air. By day 3, PPi-PFK activity increased 3.6- and 2.2-fold in samples under $0.5 \% \mathrm{O}_{2}$ and $2 \% \mathrm{O}_{2}$ at $15 \mathrm{C}$, respectively, and 1.9and 1.4-fold in samples under $0.5 \% \mathrm{O}_{2}$ and $2 \% \mathrm{O}_{2}$ at $5 \mathrm{C}$, respectively. The time, amount, and pattern of change in the levels of PPiPFK activity were similar to changes in F1,6P and RQ. The effect of mechanical stress on PPi-PFK activity in carrots caused by processing can be ruled out under our experimental conditions because there were no changes in carrots under air (Figs. 5 and 6).

ATP-PFK activity did not change during storage, and the rate was similar at different $\mathrm{O}_{2}$ atmospheres and temperatures (Figs. 5 and 6). The lack of change of ATP-PFK activity under low $\mathrm{O}_{2}$ has been reported previously (Black et al., 1987; Mertens et al., 1990) and support the conclusion that ATP-PFK activity is not affected by low $\mathrm{O}_{2}$. Under high $\mathrm{CO}_{2}(10 \%)$ storage of pears, Kerbel et al. (1988) reported a significant reduction in activities of both ATPPFK and PPi-PFK. Apparently, low $\mathrm{O}_{2}$ and high $\mathrm{CO}_{2}$ do not have a similar effect on these enzymes.

ATP-PFK catalyzes the formation of F1,6P and ADP from F6P and ATP. PPi-PFK catalyzes the reaction in the same direction, but with the formation of F1,6P and Pi from F6P and PPi. Since it also catalyzes the reaction in the reverse direction, PPi-PFK can theoretically catalyze both glycolytic and gluconeogenic carbon flow (Black et al., 1987; Stitt, 1990). Several lines of evidence suggest that $\mathrm{F} 2,6 \mathrm{P}$ is an activator of PPi-PFK in the glycolytic

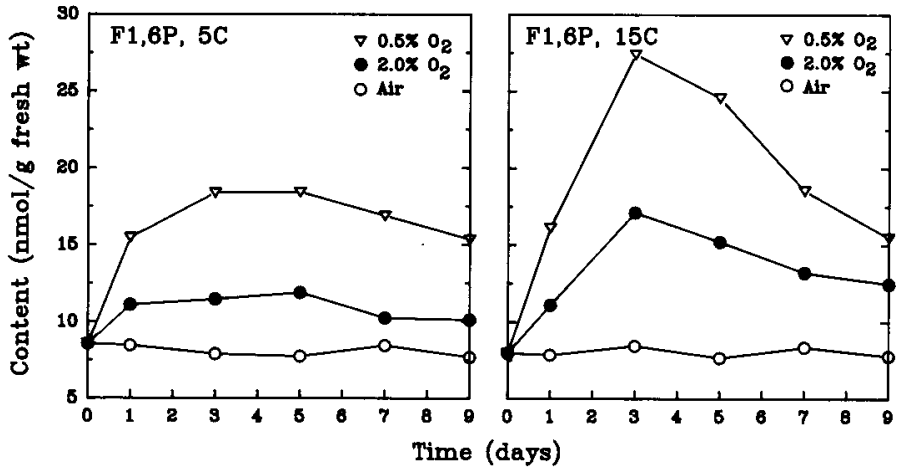

4. Changes in F1,6P content in carrot shreds held in $0.5 \% \mathrm{O}_{2}, 2 \% \mathrm{O}_{2}$, or air atmospheres it $5 \mathrm{C}$ and $15 \mathrm{C}$. Each point represents the mean of two to three determinations with the same extract. The experiment was repeated three times with similar results.

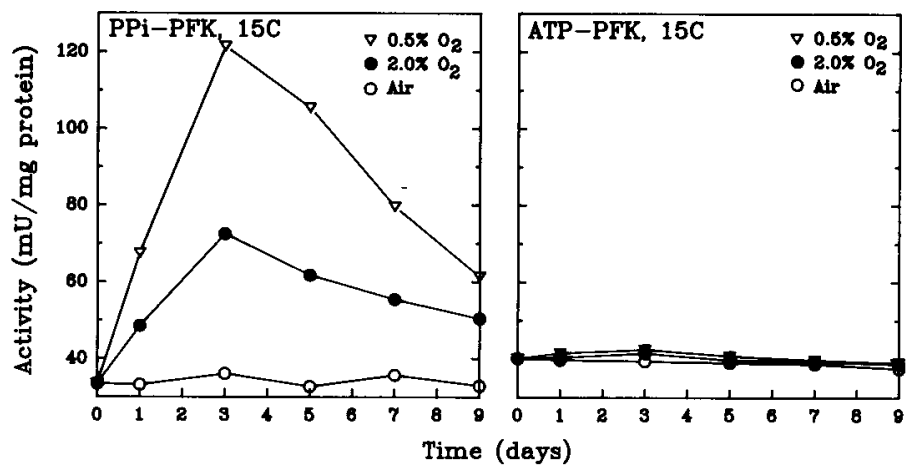

Fig. 5. Changes in PPi-PFK and ATF-PFK activities in carrot shreds held in $0.5 \% \mathrm{O}, 2 \%$ $\mathrm{O}_{2}$, or air atmospheres at $15 \mathrm{C}$. Each point represents the mean of two to three assays with the same extract. The experiment was repeated three times with similar results.

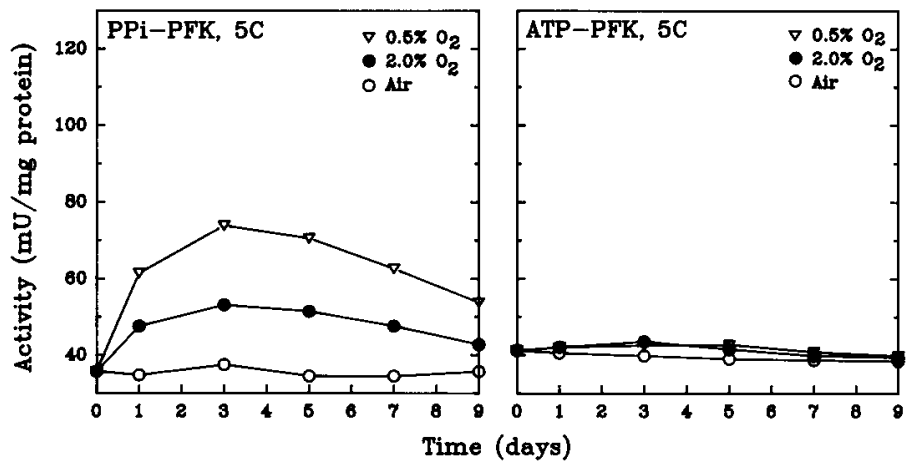

6. Changes in PPi-PFK and ATP-PFK activities in caret shreds held in $0.5 \% \mathrm{O}_{2}, 2 \%$ $\mathrm{O}_{2}$, or air atmospheres at $5 \mathrm{C}$. Other conditions are the same as described in Fig. 5.

direction (Bennett et al., 1987; Mertens et al., 1990; Smyth et. al., 1984b; Tobias et al., 1992). The amount of F2,6P increases substantially under anaerobic conditions when glycolysis becomes very active (Mertens et al., 1987) and also in the presence of an uncoupler (Hatzfeld et al., 1989). In the present paper, F2,6P content was not determined. The effect of low $\mathrm{O}_{2}$ on F2,6P content in carrots, which is essential to determine the active direction of PPi-PFK in situ, is under investigation.

In summary, low $\mathrm{O}_{2}$ atmospheres increased the RQ, F1,6P level and PPi-PFK activity but not ATP-PFK activity. These findings indicate that PPi-PFK may contribute to the regulation of glycolysis under low $\mathrm{O}_{2}$ atmospheres, and that could be a controlling point in the glycolytic pathway affected by low $\mathrm{O}_{2}$. 


\section{Literature Cited}

Bradford, M.M. 1976. A rapid and sensitive method for the quantitation of microgram quantities of protein utilizing the principle of protein-dye binding. Anal. Biochem. 72:248-254.

Bennet, A.B., G.M. Smith, and B.G. Nichols. 1987. Regulation of climacteric respiration in ripening avocado fruit. Plant Physiol. 83:973-976.

Bergmeyer, H.U. 1983. Methods of enzymatic analysis. Verlag Chemie Weniheim. Academic Press, New York.

Black, C.C., L. Mustardy, S.S. Sung, P.P. Kormanik, D.-P. Xu, and N. Paz. 1987. Regulation and roles for alternative pathways of hexose metabolism in plants. Physiol. Plant. 69:387-394.

Hardenburg, R.E., A.E. Watada, and C.Y. Wang. 1990. The commercial storage of fruits, vegetables, and florist and nursery stocks. Agr. Handbook no. 66. USDA/ARS. U.S. Govt. Printing Office, Wash. D.C.

Hatzfeld, W.D., J. Dancer, and M. Stitt. 1989. Direct evidence that pyrophosphate: fructose-6-phosphate phosphotransferase can act as a glycolytic enzyme in plants. FEBS Lett. 254:215-218.

Isenberg, F.M.R. 1979. Controlled atmosphere storage of vegetables. Hort. Rev. $1: 337-395$.

Kader, A.A. 1986. Biochemical and physiological basis for effects of controlled and modified atmospheres on fruits and vegetables. Food Technol. 40:99-104.

Kanellis, A.K., T. Solomos, and K.A. Roubelakis-Angelakis. 1991. Suppression of cellulase and polygalacturonase and induction of alcohol dehydrogenase isozymes in avocado fruit mesocarp subjected to low oxygen stress. Plant Physiol. 96:269-274.

Ke, D., E. Yahia, M. Mateos, and A.A. Kader, 1994. Ethanolic fermentation of 'Bartlett' pears as influenced by ripening stage and atmospheric composition. J. Amer. Soc. Hort. Sci. 119:976-982.

Kennedy, R.A., M.E. Rumpho, and T.C. Fox. 1992. Anaerobic metabolism in plants. Plant Physiol. 100: 1-6.

Kerbel, E.L., A.A. Kader, and R.J. Romani. 1988. Effects of elevated CO, concentrations on glycolysis in intact 'Bartlett' pear fruit. Plant Physiol. 86:1205-1209.

Leshuk, J.A. and M.E. Saltveit, Jr. 1991. Effects of rapid changes in oxygen concentration on the respiration of carrot roots. Physiol. Plant. 82:559-568

Mertens, E., E. Van Schaftingen, and H.G. Hers. 1987. Fructose 2,6bisphosphate and the control of the energy charge in higher plants. FEBS Lett. 221:124-128.
Mertens, E., Y. Larondelle, and H.G. Hers. 1990. Induction of pyrophosphate:fructose 6-phosphate 1-phosphotransferase by anoxia in rice seedlings. Plant Physiol. 93:584-587.

Mocquot, B.C. Prat, C. Mouches, and P. Pradet. 1981. Effect of anoxia on energy charge and protein synthesis in rice embryo. Plant Physiol. 68:636-640.

Nichols, W.C. and M.E. Patterson. 1987. Ethanol accumulation and poststorage quality of 'Delicious' apples during short-term, low- $\mathrm{O}_{2}, \mathrm{CA}$ storage. HortScience 22:89-92.

Smilanick, J.L. and D.C. Fouse. 1989. Quality of nectarines stored in insecticidal low- $\mathrm{O}_{2}$ atmospheres at 5 and 15C. J. Amer. Soc. Hort. Sci. 114:431-436.

Smyth, D.A., M.-X. Wu, and C.C. Black. 1984a. Phosphofructokinase and fructose 2,6-bisphosphate activities in developing corn seedlings (Zea mays L.). Plant Sci. Lett. 33:61-70.

Smyth, D.A., M.-X. Wu, and C.C. Black. 1984b. Pyrophosphate and fructose 2,6-bisphosphate effects on glycolysis in pea seed extracts. Plant Plysiol. 76:316-320.

Smock, R.M. 1979. Controlled atmosphere storage of fruits. Hort. Rev. 1:301-336.

Solomos, T. 1983. Respiration and energy metabolism in senescing plant tissues, pp. 61-98. In: M. Lieberman (cd.). Postharvest physiology and crop preservation. Plenum Press, New York.

Stitt, M. 1990. Fructose-2,6-bisphosphate as a regulatory molecule in plants. Ann. Rev. Plant Physiol. Plant Mol. Biol. 41:153-185.

Thomas, M. 1929. The production of ethyl alcohol and acetaldehyde by apples in relation to the injuries occurring in storage. Part I. Injuries to apples occurring in the absence of oxygen and in certain mixtures of carbon dioxide and oxygen. Ann. Appl. Biol. 16:444-458.

Tobias, R.B., C.D. Boyer, and J.C. Shannon. 1992. Enzymes catalyzing the reversible conversion of fructose-6-phosphate and fructose-1,6bisphosphate in maize (Zeu mays L.) kernels. Plant Physiol. 99: 140-145.

Wang, C.Y. 1990. Physiological and biochemical effects of controlled atmosphere on fruits and vegetables, p. 197-223. In:M. Calderon and R. Barkai-Golan (eds.). Food preservatives by modified atmospheres. CRC Press, Boca Raton, Fla.

Weichmann, J. 1986. The effect of controlled-aatmosphere storage on the sensory and nutritional quality of fruits and vegetables. Hort. Rev. 8:101-127.

Weichmann, J. 1987. Low oxygen effects, p. 23 1-237. In: J. Weichmann (cd.). Postharvest physiology of vegetables. M. Dekker, New York. 